Bolm Inst. oceanogr., S Paulo, 32(1):99-103, 1983

\title{
BIOLOGICAL RESOURCES OF THE ANTARCTIC KRILL BY T,C, LUBIMOVA, EDITOR, VNIRO, 1980 (MIMEOGRAPHED): A BOOK REVIEW
}

Stanis law RAKUSA-SUSZCZEWSKI

Polish Academy of Sciences*

In 1980, Biological Resources of the Antarctic Krill edited by T. C. Lubimova and published by VNIRO appeared in rotoprint. The book begins with a short preface and contains 12 papers in Russian with brief summaries and a table of contents in English. In total, there are 250 pages of text with 46 drawings and 14 tables. The papers presented in this volume are discussions of the results from investigations of the authors themselves and from the literature, with 323 publications from the USSR and other countries being cited. The book reviews a series of very important questions about the environmental conditions, distribution and biology of krill and other living resources of the Antarctic, and discusses the legal aspects of their exploitation. This review will attempt to select from these texts original hypothesis and/or concepts which are verified by documentary evidence and which, in my opinion, are worthy of further investigation.

The anonymous author of the preface asserts that the latest USSR investigations confirm earlier estimates of the size of the stocks of biological resources of the Antarctic. Reference to the FAO Conference of 1979 sets estimates of possible catches of krill at up to 50 million tons per year.

The first paper by Maslennikov deals with the circulation of Antarctic waters and its relation to the distribution of krill. In the opinion of the author the area of the drift and mass occurrence of krill is smaller than the area within the boundary proposed by Nemoto (1962) and Mackintosh (1973), and therefore the estimates of krill biomass in the Antarctic must be regarded as overstated. Assuming passive migration of Euphausia superba, Maslennikov concludes that water currents and dynamics play a decisive role in krill distribution. Based on

(*) Dziekanōw Leśnyy,

05-150 Lomianki, Poland.

Publ. n. 589 do Inst. oceanogr. da Usp. the analyses of hydrological and hydrochemical data, together with information about the drift of icebergs and ice, both of which may serve as indicators of the movements of water masses, Maslennikov presents a general scheme of the circulation in the regions of massoccurrence of krill. These regions are the more or less closed areas of cyclonic circulation occurring in the regions of the Wedde11, Lazariev, Riser-Larsen, Cosmonauts Davis, Sotrudnicestva, Ross, Amundsen and Bellingshausen Seas and of Prydz Bay. Cyclonic whirls form in the areas between the southern limits of the Antarctic Circumpolar Current (ACC) and the waters of the higher latitudes associated with the East Wind Drift (EWD). Regions with cyclonic circulation may border upon smaller areas of anticyclonic water circulation. The boundaries of these areas may vary, just as the type of circulation may change from cyclonic to anticyclonic. Prydz Bay is an example of such a situation. In the areas of cyclonic circulation where the ACC swerves northward, krill may be "thrown out" and into the vicinity of the Convergence. Yet, in areas where the ACC approaches the continent, as in the Bellingshausen Sea or in the regions near the Antarctic Peninsula, the migration of krill does not occur. The return of krill southward is associated with the drift of the waters of the eastern arms of the cyclonic gyres. Such situations occur mainly in the regions between $20^{\circ}-30^{\circ} \mathrm{E}, 90^{\circ}-100^{\circ} \mathrm{E}$ and $140^{\circ}-160^{\circ} \mathrm{W}, 85^{\circ}-110^{\circ} \mathrm{W}$ and at $20^{\circ} \mathrm{W}$. The distribution of krill associated with circulation zones seems to be one of the most important of the adaptations of krill populations. Maslennikov suggests the existence of separate subpopulations of krill connected with the various gyres.

Bogdanov et al discuss the relation between the Secondary Frontal Zone (SFZ) and the expansion of krill swarms in the Scotia Sea in 1979. The SFZ forms on the southern border between the ACC and 
the waters of the Weddell Sea. Water from the Bransfield Strait, with a characteristic salinity of $34 \%$ $34.1 \%$, moving northeastward also play a part in the formation of the SFZ in the region. The position of the SFZ varies not only from year to year but also during the spring-summer seasons. Since the waters in this area are weakly stratified, the relief of the bottom has a substantial influence on the direction of the currents and the position of the $\mathrm{SFZ}$. In this region the isotherm $1.3^{\circ} \mathrm{C}$ or the isotherms $1.7^{\circ} \mathrm{C}$ and $0.7^{\circ} \mathrm{C}$, corresponding to the maximum temperatures of the intermittent water layers, may serve as an indicator of the SFZ, as they are characteristic of the mixed waters of various origins which extend over the northern and southern borders of the water mixing zone. The geostrophic currents at the level of $1000 \mathrm{db}$ reflect the position of the $\mathrm{SFZ}$. In the region of the South Orkney Island in 1978 and 1979 , the meanders of the SFZ stretched along the geographical longitude. At a distance of 100-150 miles northeastward, large concentrations of krill were found.

Popkov \& Elizarov give careful consideration to the effects of nutrients, solar radiation, and the stability of the surface water layer upon the primary production in the Pacific Sector of the Antarctic. In high latitudes, nutrients are in abundant supply. Solar energy depends on the particular latitude and determines phytoplankton productivity. At $60^{\circ} \mathrm{S}$ latitude the period of minimal solar energy lasts from May to August and at $70^{\circ} \mathrm{S}$ from April to July. The presence of ice reduces the quantity of energy reaching underlying waters. The authors analyse the expansion of ice in the region under investigation from November to March of the years 1972-1976. Four ice-free streams running along geographical latitudes are noted. Stability of the water column is determined not only by temperature but also by variations of salinity caused by icemelting. Data from 700 hydrological stations and records from the period 1970-1977 were used to chart water stability. Calculations were based on the formula of Hesselberg and Sverdrup. In the area under investigation essential differences were found between regions east and west of $130^{\circ}-140^{\circ}$ longitude.

Popkov \& Elizarov presume that the development of phytoplankton is controlled by water column stability. When the thickness of the compensate depth becomes shallower than that of the mixed layer, the phytoplankton are prevented from remaining in the optimum high zone long enough for extensive production. Thus the shallower the euphotic zone and the depth of the $E_{\max }$ values, the greater the productivity of phytoplankton. The compensation point in this region ( $1 \%$ light energy) occurred at a depth of 7 to $95 \mathrm{~m}$, and in $78 \%$ of the examined cases, at a depth of $50 \mathrm{~m}$. Based on stability indices, three zones of potentially high productivity were discerned. In the Amundsen and Bellingshausen Seas, the region along the continental slope in the vicinity of the southern boundary of the ACC should be highly productive. In the western part of the investigated areas there are two zones of potentially high production: one, running from the SE to the NW along the slope of the Ross Sea shelf and the other in the region of Balleny Isl and which is much smaller and not continuous.

Bogdanov et al. discuss the conditions of the environment and distribution of krill of the Antarctic Peninsula. The occurrence of kril swarms is conditioned by hydrodynamic processes. In the investigated region the SFZ forms at the boundary between the ACC and the shelf waters of the Antarctic Peninsula. In 1978 the waters of the ACC entered far into the shelf area of the Peninsula and caused the formation of a we11-developed system of meanders, thus favoring the formation of krill swarms. A different situation was observed in 1979 when the ACC deviated northward and the SFZ did not meander. In that year, scarce and swarms were rare。 Locally, currents may meander in response to bottom topography. Such a situation was observed in the region north of the South Shetlands where the existence of a weak cyclonic whirl had its axis stretching along the Palmer Archipelago. The Bransfield Strait is a place of special interest. Marked seasonal changes in hydrology may occur here from year to year. Along the southern shores of the South Shetlands a strong current (up to $50 \mathrm{~cm} / \mathrm{s}$ ) moving from the west northeastwards was observed to carry the shelf waters of the Antarctic Peninsula into the Bransfield 
Strait. The waters from the Weddell Sea entered from the southeast, and it seems likely that krill populations from the Wedde 11 and Bellingshausen Seas would meet in the Bransfield Strait. In 1978 and 1979 large swarms of krill were observed in the NE region of the Bransfield Strait.

The paper by Arzanova \& Michajlovskij deals with hydrochemical conditions in the regions of krill swarms in the southern part of the Scotia Sea and west of the Antarcti.c Peninsula. The best hydrochemical indicators of the mixed waters where krill swarms occur are $\mathrm{O}_{2}$, $\mathrm{Si}$ and the Si/P ratio. The oxygen content in the minimum $\mathrm{O}_{2}$ layer, i.e., at $250-300 \mathrm{~m}$, increases from the north to the south. In the region under investigation the extreme values of $\mathrm{O}_{2}$ content were recorded in the waters of the ACC and the Weddell Sea. A similar situation can be observed north of the South Shetlands. In the western part of this region the $0_{2}$ gradient is smaller than in the Scotia Sea. Since the waters of the ACC enter deep into the shelf area of the Antarctic Peninsula, shallow depths preclude an oxygen minimum. The Bransfield Strait has a unique character owing to the mixing of waters from the east and the west. The oxygen content is higher than in the Weddell Sea and the oxygen gradient is very small, evidencing the thorough mixing of these waters. On the whole, the oxygen content of the waters in the Bransfield Strait decreases rapidly from west to east, especially in the area of mixing of local Weddell Sea waters. The percent saturation of oxygen in Weddell Sea water may serve as a good indicator of the origin of the oxygen minimum layer. On the average, the saturation values of the ACC amount to $73 \%, 65 \%$ and $52 \%$, respectively. The oxygen minimum layer nearest the water surface occurs in the area of the mixed waters of various origin. Nearest to the surface is the oxygen minimum layer where the decrease in oxygen in the summer temperature minimum layer is faster in the surface water and consequently the oxygen content is lower in the area of mixed waters as compared with the neighbouring waters.

It is not so much the absolute value of silicate as the gradient of $\mathrm{Si}$ content, especially at the depth of $50 \mathrm{~m}$, which may serve as a good indicator of the area of the meeting and mixing of waters of various resources. In the investigated area two types of water may be differentiated: one is characterized by a small vertical gradient in which the $\mathrm{Si}$ concentration reaches its maximum at a depth of $1000 \mathrm{~m}$; another is characterized by a large gradient resulting from a decrease in the $\mathrm{Si}$ content in the layer from 200-300 m.

The best bydrochemical indicador of zont of water mixing is the Si/P ratio. This ratio generally increased from the north to the south. In the region of the SFZ the value of the $\mathrm{Si} / \mathrm{P}$ ratio ranges from 20 to 35, averaging 33. At the southern boundary of the $\mathrm{ACC}$, the $\mathrm{Si} / \mathrm{P}$ ratio increases with increasing depth. In the Wedde11 Sea and around the Antarctic Peninsula the lowest values of the $\mathrm{Si} / \mathrm{P}$ ratio occur in the intermediate layers of the cold water masses. During the phytoplankton growth season the Si/P ratio is subject to variation.

Makarov analyses the long period of observation of the distribution of the length-groups of $E$. superba populations in the regions of the Scotia Sea, the northern part of the Weddell Sea, and especially the area near the South Orkneys. Based on data from the years $1965,1967,1968,1979,1971,1974$ and 1975, the author contents that the distribution of the size-groups of the populations investigated during the same seasons of various years gives information about the life cycle of the species and the conditions for growth. Analysis of material from commercial trawls enabled the author to single out two size-groups: juveniles and adults.

The SFZ divides krill populations into larger individuals to the north and smaller ones to the south. When the SFZ meanders, the situation may be reversed. In the region of the South Orkneys, the larger individuals are from the Bellingshausen Sea, while the smaller are from the Weddell Sea and Bransfield Strait. The differences in the size of krill result from an earlier occurrence of spring in the north than in the south and the more favourable conditions for individual development of krill. In the investigated region six size-group may be found corresponding to three pairs of subpopulations from the Bellingshausen and Weddell Seas and the 
Bransfield Strait. The life span of krill is still unknown. Based on the analyses of material from 1965, Makarov presumes that krill may even live as long as 6-7 years.

Makarov et. al. discuss the distribution and formation of krill swarms, taking by way of example selected regions in the Antarctic sector of the Atlantic and Pacific Oceans. Irregularity is a characteristic feature of krill distribution in these regions. The area of krill occurrence is limited to higher latitudes and the appearance of krill within the ACC is associated with the "throw out" of krill by the large cyclonic whirls. Dynamics of the waters is the main factor not only in controlling the distribution and displacement of the species but also in the maintenance of a population within a defined area or in the exchange of individuals among populations. Conce trations of krill form when cyclonic whirls border anticyclonic ones and create zones of "down welling". Such areas were observed to the NW and $\mathrm{NE}$ of the South Orkneys. The region around South Georgia is, in the opinion of the authors, the ultimate place of krill migration. Krill may be, occasionally scattered by the SFZ, but a favourable circulation of the waters in the vicinity of South Georgia causes concentration of krill in this region. However, the main density of krill is brought into the region of South Georgia by the inflow of water from the Weddell Sea. The authors corroborate the fact of the formation of the SFZ in the Pacific sector analogous to that observed in the Scotia Sea Among the biological causes of the formation of krill swarms are reproductive processes which, during a warm summer season, occur earlier. Krill swarms are also subject to phytoplankton patchiness. Many questions remain unanswered

although it may be staked that the place and the manner of swarm formation is controlled by hydrodynamic factors; whereas, the causes and the timing of the formation are controlled by biological factors.

Sysoeva \& Sevcov discuss the distribution of the size-groups and the biological condition of $E$. superba populations in the region surrounding South Georgia in the autumn of 1977 and compare their data with the records from previous years. In 1977 exceptionally large specimens were observed, measuring $38-40,42-44$ and $50-52 \mathrm{~mm}$ in modal length. The distribution of krill swarms, concentrated in the region of the Cumberland-West Bay Channel, was much the same as in 1968. In 1965, 1967, 1970 and 1976, young, 25-42 mm long individuals predominated. The reproduction of krill in the region of South Georgia is very 1 imited. Larvae are scarce and the presence of krill depends mainly on the inflow of water from the Weddel1 Sea. In 1977 the reproduction of $\mathrm{krill}$ in the neighbourhood of South Georgia ended in the latter part of March and the early part of April. The authors emphasize the importance of bottom topography in the formation of whirls, which favours the formation of krill swarms.

The paper by Storozuk et al. deals with the content of metals, lipids, protein and ash in the bodies of krill caught in the region of the Bellingshausen and Scotia Seas during the period from February to April 1977. The Fe, Mn, Zn, $\mathrm{Cu}, \mathrm{Ni}, \mathrm{Co}, \mathrm{Sr}, \mathrm{Pb}$ and $\mathrm{Cd}$ contents are given as $\mathrm{mg} / \mathrm{kg}$ wet weight, taking note of the sex and stage of krill development. Fourfold to tenfold differences in metal content were found in the analyzed samples. The content of metals, except $\mathrm{Fe}, \mathrm{Mn}$ and $\mathrm{Zn}$, in mature males from the Bellingshausen Sea was higher than in mature females which utilize these chemical elements in their reproductive processes. The $\mathrm{Fe}, \mathrm{Mn}$ and $\mathrm{Zn}$ concentrations increase with the development of the ovaries. The authors associate this increase with the increase of 1ipolytic metaloproteins in females. The lipid content in females may be three times higher than in males. On the other hand, males showed a higher content of $\mathrm{Cu}, \mathrm{Ni}$ and $\mathrm{Co}$, which seems to be connected with larger quantities of ash in males than in females. Young females and males contained similar amounts of metal, lipids, protein, water and ash. The differences in the content of metals between the two sexes result from regenerative functions. The content of metals increase with growth of krill. The concentration of metals, except Fe and $\mathrm{Cd}$, depends also on feeding and was higher in individuals not taking food. The contents of $\mathrm{Cu}, \mathrm{Ni}, \mathrm{Zn}$ and $\mathrm{Cd}$, when compared for the same stages of develop- 
ment, size, and sex, were higher in krill from the Bellingshausen Sea than in krill from the Scotia Sea.

Naumov \& Cekunova discuss the problems associated with respiration, production and consumption of $E_{\text {o superba. Besides }}$ reporting krill respiration at temperatures of $2^{\circ}, 5^{\circ}$ and $7^{\circ} \mathrm{C}$ and giving wet weight/length values for various stages of krill development, the authors discuss a series of theoretical proposition, among which is the estimate of probable krill life span 2.5 years. Using this life span, cumulative parameters of the energy budget were calculated.

Lubimova \& Sust consider questions regarding the utilization of krill by the main groups of consumers in the Antarctic. At present it is impossible to determine the effect of the commercial exploitation of krill upon the ecosystem. In the past, the numerous baleen whales, as migrant organisms, removed from Antarctic regions about $41.7 \%$ of the energy in the form of fat accumulated in the course of feeding. This corresponded to about $60-70$ million tons of krill per year. At present the amount of krill consumed by whales is estimated at 9.7 million tons per year. Thus, in the opinion of the authors, over 60 million tons of krill remain in the Antarctic ecosystem. Although there are other predators of krill, it does not seem that they have increased. The authors estimated annual fish production to be $3.75-4.2$ million tons, fish biomass at $14.1-15.75$ million tons, and consumption of krill ( $E_{0}$ superba and $E$. crystallorophias) by fish at 28 million tons per year. The consumption of krill by cephalopods is estimated to be 50-53 million tons per year.

The last paper by Fedorov \& Malysev is devoted to the problems of exploitation of biological resources of the Southern Ocean discussed against the background of the recommendations of the Antarctic Treaty. The interests of many countries are turning toward regions which have the status of an open sea, which includes the Antarctic. The authors discuss the Antarctic Treaty and its regulations, including the essential limitation of human activities. They note progress of international fishing and conservation agreements. This is evidenced by gradual transition from the general principles of natural conservation, worked out by the membercountries of the Antarctic Treaty, through the Convention on Seals, to be recently ratified Convention on the Conservation of Living Resources of the Antarctic. This transation, in the opinion of the authors, manifests tendencies toward consolidation of the rights of a single State or a group of States incontrolling industrial fisheries in open sea zones. A particular responsability for the maintenance of living resources of the Antarctic at a proper level rests with the SCAR. In the last few years this organization has established a Group of Specialists together with another Working Group on the subject of biological resources. When the Convention on the Conservation of Living Resources of the Antarctic comes into force, it will still not be advisable to separate immediately the activities of the SCAR Group of Specialists from the future Scientific Committee of the Convention. It may be expected that the Convention will utilize the recommendations of the Group of Specialists, treating them as scientific advisers.

In the future, the Scientific Committee and the Commission of the Convention should cooperate in order to secure, on the basis of comprehensive, scientific information, a balance between the most effective principles of natural conservation on the one hand, and the exploitation of biological resources of the Antarctic, on the other hand. Therefore, all of the interested States and the Signatories of the Antarctic Treaty in particular should have a realistic attitude toward reciprocal relations within the framework of the Convention. Such cooperation is particularly necessary when considering increasing pressure from the Third World States, which claim a part of the profits of the exploitation of the "common heritage" of the open sea. It may be expected that by the time the Convention on the Conservation of Living Resources comes into force, a more complex stage of the international control of man's activities in the Antarctic will have been set.

(Received 05-May-1983; accepted 15-Aug-1983) 